\title{
BARBARA KONNEKER Y LA CRÍTICA DE LA NARRENIDEE
}

El estudio de Barbara Konneker ${ }^{1}$ constituye desde hace tiempo - al menos en el ámbito de lengua alemana - una obra básica entre las dedicadas a la literatura del "loco" de los siglos XV y XVI. Desde su aparición en 1966, el libro despertó gran interés y fue ampliamente reseñado por los estudiosos germánicos, lo mismo que por anglosajones y franceses ${ }^{2}$. Sin embargo, en el mundo de habla española, al parecer, pasó casi inadvertido, a pesar de que el tema del "loco" fue, hasta entrado el siglo XVII y por encima de todas las fronteras lingüísticas, un tema dominante de la época.

El importante estudio de Konneker representa el intento de mostrar la idea del "loco" como una categoría central y universal del pensamiento humanista. El objeto de su investigación no abarca toda la literatura del "loco" de esa época (ello implicaría la inclusión del teatro, los libros populares, las colecciones de chascarrillos y libelos), sino que se limita deliberadamente a las obras principales de los autores más conocidos: Sebastian Brant, Thomas Murner y Erasmo de Rotterdam. Esta limitación temática ocasiona ciertamente que, por una parte, la imagen del "loco" en la literatura de la época no pueda abarcarse en toda su complejidad; y por otra, que a pesar de esto se sigan los aspectos centrales de la idea del "loco" a través de todas las obras, facilitándose así una mejor comprensión de los cambios fundamentales en la

${ }^{1}$ Barbara Konneker, Wesen und Wandlung der Narrenidee im Zeitalter des Humanismus. Brant-Murner-Erasmus, Wiesbaden, 1966.

${ }^{2}$ Véanse las reseñas de F. J. STOPP ( $\left.M L R, 62,1967,740-742\right)$; O. HerDING (Arcadia, 2, 1967, 324 s.); E. Sobel (GRev, 43, 1968, 154-157); A. HAAS $(W W, 18,1968,375$ s. $)$; y G. Pauline (Era, 20, 1968, 604-607). 
imagen del hombre en la época de transición hacia la Edad Moderna.

Metodológicamente, la autora empleó los instrumentos de la historia de las ideas y la historia de los temas. Por ello, en el análisis y la interpretación de cada obra, la visión abarca relaciones concatenadas, sobre todo en el terreno de la teología y de la antropología. En consecuencia, el libro abre con un capítulo sobre el origen del motivo del "loco" alrededor de 1500 y sus raíces espirituales y temáticas en las postrimerías de la Edad Media.

Este primer capítulo representa una introducción a la obra de Sebastian Brant, a quien se reconoce como una figura clave a finales del medievo. El estudio pone de manifiesto que el concepto de "loco" que tenía Brant, pese a seguir éste la literatura sapiencial del Antiguo Testamento, no puede encasillarse sin más en la tradición medieval de la stultitia-sapientia, sino que surge de la amplia crisis de conciencia espiritual y religiosa del fin de la Edad Media. La autora considera que la base espiritual que nutre al concepto del "loco" brantiano, se localiza en la literatura didáctica de la tardía Edad Media, que manifiesta ya una creciente orientación hacia la vida terrenal, así como un cambio en la conciencia de valores: los vicios humanos ya no se contemplan sin más como pecado, sino como consecuencia de la falta del natural conocimiento, causada por razones subjetivas. El logro creador de Brant consiste, sobre todo, en amalgamar las múltiples tendencias de la didáctica de la baja Edad Media y subordinarlas a la idea central del "loco". Este tipo de "loco", tal como Brant lo concibe, se convierte en la encarnación de todos los defectos perniciosos que censuraba la didáctica de la época. Con todo, representa a sí mismo el correlato negativo de cuanto ofrecía de positivo aquella literatura.

Para la autora el modelo y el prototipo vivo de este género de "loco" está en la farsa carnavalesca del siglo XV, con todas sus libertades en lo que se refiere al ambiente vital y sensual. No obstante, hay que señalar a este respecto que la intención de la farsa carnavalesca no es la de una didáctica negativa; no censura la "locura', del hombre, sino que presenta la liberación de ambientes vitales por lo general tabúes, como la liberación de coacciones existentes en el ámbito de la vida cotidiana. Además, quien simboliza la condición primaria de la existencia creada no es el "loco", sino el campesino. Cuando los "locos" aparecen en la farsa carnavalesca, no pueden cuajar en un tipo determinado y representan modos de comportamiento muy diversos.

El capítulo 2 está dedicado a La nave de los locos (1494) de Brant, 
la obra en que la figura del "loco' adquiere su configuración clásica. La atención no se centra tanto en la composición de la obra, que la autora clasifica como una sucesión arbitraria de capítulos con bruscos cambios de tema, como en el concepto ético y religioso que Brant tiene del "loco" en sus diferentes manifestaciones. La sorglich stat de la locura, es decir, la situación grave y preñada de peligros en la que se encuentra el "loco" no es consecuencia del pecado, sino efecto de la obcecación espiritual y de la falta de inteligencia. Por ello, el único remedio contra la ceguera del "loco" no es la conversión religiosa, la penitencia y el perdón de Dios, sino únicamente el conocimiento propio en cuanto persona aquejada por la " locura". Existen evidentes paralelos con el concepto cristiano del pecado - cada cual es un "loco" en potencia y está amenazado por la condenación. Sin embargo, Brant realiza un cambio de signo racionalista y una trasposición del sentido: el conocimiento de sí mismo que postula conduce a la curación espontánea, incluso a la propia salvación, y así, en La nave de los locos faltan, en consecuencia, las referencias a Cristo y a los sacramentos de la Iglesia, aunque Brant defiende naturalmente una ética arraigada en la fe cristiana y se preocupa por la continuidad de un mundo de orientación cristiana.

A pesar de su lealtad a la Iglesia y su preocupación por la continuidad del orden temporal y religioso, Brant, en opinión de la autora, contribuye considerablemente con su obra a descomponer la visión medieval del mundo y a socavar sus fundamentos religiosos y eclesiásticos. Con ello, la autora rechaza una interpretación "cristiana" de La nave de los locos, destacando, en cambio, la confianza moralista que Brant tiene en el simple buen sentido. Aunque la investigación reciente haya criticado el hecho de que se diera una importancia exagerada a esta intencionalidad mundana, habrá que sostener la tesis de que Brant transformó y aun socavó ciertos conceptos cristianos y religiosos con su idea del "loco". Lo confirma, no en último lugar, la imagen que Brant tiene de Dios: un ser justiciero y riguroso, semejante al Dios del Antiguo Testamento, lo cual presta a la obra algo de sombrío y amenazador. Este Dios que castiga implacablemente no es sino la personificación de una ética, cuasi ley, únicamente referida al hombre y alumbrada por la inteligencia. La autora lo interpreta no sólo como expresión de una situación de crisis general, sino también como efecto de la experiencia religiosa y personal de Brant, para quien la inteligencia debía de suplir la fuerza menguante de la convicción cristiana y religiosa.

En La nave de los locos, la auténtica experiencia religiosa queda 
reducida en gran parte a una religión de ley rígida y moralizada, de la que Brant deduce sus rigurosas exigencias éticas. La confianza en la gracia y en la misericordia se censura como un fatídico error de conocimiento en un mundo que ha caído en la "locura". A este respecto, la autora señala el concepto fundamentalmente opuesto de Lutero.

Esta actitud de Brant, guiada por la inteligencia y fijada en la conservación de lo existente, queda cubierta en la obra por una resignación escéptica, de desprecio del mundo y del miedo no vencido a la muerte. A la par que se evoca continuamente la posibilidad de mejorar el mundo y de la salvación propia, la obra se caracteriza por una actitud fundamentalmente pesimista. Por eso, Brant desarrolla de una manera especialmente sugestiva la visión del fin del mundo y del fracaso de todos los esfuerzos. Y la época proporcionaba un símbolo apocalíptico particularmente apropiado para el tema de la navegación de los "locos": el naufragio.

Según esta interpretación, el concepto brantiano del mundo resulta una extraña mezcla de desprecio escéptico del mismo mundo y de confianza en el sentido común moralista --una visión del mundo particularmente desgarrada y contradictoria que Konneker considera, con acierto, como síntoma de una época de transición y de crisis. El desacuerdo con respecto al lugar que ocupa Brant en la historia de las ideas en el umbral de la Edad Moderna, se manifiesta en que, por una parte, proclama el ideal del hombre determinado por la razón, independiente de autoridades, cuyo símbolo es el sabio que se conoce a sí mismo; y por otra, descompone, desde dentro, con esta visión del hombre, precisamente el orden y los valores que con tanto tesón trata de conservar. Debido a esta diversidad de planos, La nave de los locos de Brant es considerada como una típica obra de transición.

El capítulo 3 se ocupa de Thomas Murner, fraile franciscano de Estrasburgo y predicador popular. Con su primera obra, $\mathrm{Na}$ rrenbeschworung (La conjuración de los locos), de carácter satírico y didáctico, publicada en 1512, Murner sigue conscientemente las huellas de Brant. No obstante, la autora se opone decididamente a las investigaciones anteriores, que no vieron en Murner sino un "servil imitador" de Brant. En un párrafo extraordinariamente informativo de este capítulo, la autora expone en primer lugar el modo en que Murner se ocupa de la obra de Brant, y las relaciones literarias entre ambos, para analizar seguidamente las características del concepto del "loco" en Murner.

Murner considera al "loco" como un personaje diabólico y endemoniado, y su idea del mismo tiene un tinte decididamente 
religioso, opuesto al concepto racionalista de Brant. En tanto que Brant trata de mejorar las cosas por medio de la exhortación y aboga por el conocimiento propio, para Murner la "locura"' es ein schedlich dingk, esto es, una fuerza destructora que asalta al hombre desde fuera, amenaza su condición de ser semejante a Dios y resulta muy perniciosa. Así, el mal es un elemento integrante de la "locura" que debe ser descubierto, denunciado y condenado. De esta manera, la "locura" se equipara al pecado, es una rebelión del hombre contra Dios.

El concepto de "locura" de Brant, que partía de la capacidad del hombre para mejorar, en Murner se convierte en un arma para luchar contra el vicio, la maldad y el malestar social. La denuncia directa y la polémica caracterizan a las obras de Murner. La lucha contra los vicios de sus contemporáneos, emprendida con una pasión y una violencia despiadadas, pone de manifiesto cuán fuertemente afectan al autor los problemas de su época. Sus obras constituyen una singular mezcla de libelo y de sátira, particularmente Von dem grossen Lutherischen Narren (1522), donde polemiza contra su gran adversario Lutero. En este escrito, lo mismo que en La conjuración de los locos, el "loco" cae en una situación dudosa. Por una parte es el poseído, sin culpa alguna imputable a su persona, al cual hay que exorcizar; por otra, también es el hombre responsable de sí mismo que por libre decisión se entrega al mal, asumiendo a su vez el papel del diablo. Con esta fórmula subjetivamente negativa del concepto del "loco", Murner corre peligro de tomar incluso la libertad de hombre por una fuerza demoniaca, y entonces su idea del "loco", contradictoria e informe, difícilmente podría servir de modelo en el futuro, a pesar de toda su crítica sagaz de la época.

Murner concibe al "loco", por una parte, como hombre entregado al mal y, por otra, como una especie de ser sobrepersonal que domina al hombre y que por ello debe ser conjurado y exorcizado como un demonio. La evidente analogía con la idea del hombre poseído por el demonio, así como con la práctica del exorcismo, plantea la cuestión de su parentesco con el concepto del diablo en la tardía Edad Media, que la autora recoge en el capítulo 4. Por medio del análisis de fuentes literarias, en especial del teatro religioso, se pone de manifiesto que el concepto del "loco" en Murner debe entenderse como el lógico desarrollo ulterior de la representación del diablo en el teatro de la época. Este capítulo proporciona una mayor amplitud a la discusión científica, y hace patente que Murner no sólo se orienta por su modelo Brant, al que trata de refutar al mismo tiempo, sino que su concepto del 
"loco" está relacionado, en parte al menos, con otros contextos históricos.

El Moriae Encomium sive Stultitiae Laus de Erasmo de Rotterdam, publicado en 1511 y examinado en el capítulo 5 del estudio, representa un nuevo comienzo sorprendente y uno de los momentos de apogeo en la exposición licieraria del tema del "loco". Al comparar el Elogio de la locura de Erasmo con La nave de los locos de Brant y las obras de Murner, la autora ofrece nuevas perspectivas de interpretación. Ante todo se demuestra que Erasmo, sin ocuparse directamente de Brant, recoge su punto de partida y lo desarrolla de manera original. Erasmo vence el pesimismo de Brant y la polémica agresiva de Murner por medio de una optimista filosofía de la "locura", que no comprende la "locura" como problema moral ni la identifica con el pecado ni la maldad, sino que aplica el antagonismo necedad-sabiduría al dualismo espíritucarne, ratio y affectus. En esta antropología filosófica se equipara la sabiduría con el ámbito del espíritu, y la locura, en cambio, con el de las pasiones e instintos humanos. El nuevo y positivo conocimiento de Erasmo sostiene que la 'locura", es decir, el ámbito de los "afectos", no puede separarse de la naturaleza del hombre por su estado intermedio entre los animales y los ángeles, y debe estar en consonancia y fructífero intercambio con la ratio, todo lo cual impide su condena a priori. Dentro de esta visión del hombre, se atribuye un función positiva al affectus. Éste, sujeto al espíritu del cual es estímulo, se comprende como fuerza impulsora del hombre, quitando con ello a la idea del "loco" las ataduras de un pesimismo moral.

Konneker opina que la paradoja específicamente cristiana de la "locura en Cristo", de la "locura de la Cruz", está también incluida en esta filosofía del "loco", y que Erasmo aprovechó un juego ingenioso e irónico con convicciones fundamentales del Cristianismo, sintetizándolas en categorías filosóficas. Esta tesis en especial ha sido motivo de objeciones, y en reseñas críticas se ha llamado la atención sobre la obra que E. W. Kohls ${ }^{3}$ publicó al mismo tiempo. Kohls defiende la tesis opuesta: la filosofía de Erasmo sólo puede entenderse a partir de su teología basada en las Sagradas Escrituras.

El capítulo final se ocupa de la actitud contraria del primitivo protestantismo frente al concepto del "loco" humanista. La figura del "loco", emancipada por el humanismo de sus orígenes religiosos, tuvo que entrar en conflicto con la doctrina luterana del

${ }^{3}$ E. W. Kohls, Die Theologie des Erasmus, Basilea, 1966, 2 ts. 
pecado y de la gracia. Por eso los autores protestantes se apartan de la figura del "loco", recuperando el personaje del diablo que en el teatro del la baja Edad Media se había humanizado y ya sólo jugaba un papel cómico. La autora lo ilustra tomando por ejemplo el Panmachius (1538) de Thomas Naogeorgus. El concepto de la función del diablo en la historia sagrada, reactivada e intensificada por Lutero, desplazó la idea del "loco" que sólo pervive en las obras de algunos epígonos y ya no vuelve a ser un punto de cristalización de la visión del mundo de la época.

En un "avance", la autora esboza brevemente los cambios que sufre la idea del "loco" a finales del siglo XVI, tal y como se presenta en la figura de Eulenspiegel y en el Lalebuch, además de mencionar por último los dos tipos de "locos", completamente diferentes el uno del otro, que inauguran una nueva era: el "loco" shakesperiano y Don Quijote.

He aquí, a grandes rasgos, lo esencial de este estudio no superado hasta la fecha en lo que se refiere a la exposición extensa del tema y a su análisis persuasivo. La obra trata de comprender los profundos cambios de toda una época a través del "símbolo de la humanidad" representado por el "loco". Los resultados de la investigación de Konneker únicamente han sido corregidos de manera decisiva con respecto a la composición de La nave de los locos en dos trabajos de Ulrich Gaier ${ }^{4}$, contemporáneos del estudio de la autora. Gaier parte del elogio entusiasta que los entendidos de entonces en materia de arte hacían de la obra, calificándola de divina sátira, y analiza en detalle por vez primera su forma artística. Así llega a la conclusión de que el autor de La nave de los locos tenía conciencia de la forma, siguió principios retóricos, manejó soberanamente los diversos recursos estilísticos y creó así una obra de arte, orientada por modelos de la Antigüedad, con la que trató de revivir la sátira romana.

Después de los estudios de Gaier sobre la estructura y el estilo de La nave de los locos ha de corregirse el juicio de Konneker y de todos los estudios de Brant anteriores al suyo, que dieron por un hecho la informidad aforística de la obra y el orden arbitrario e irregular de los capítulos. Con el descubrimiento de las cualidades artísticas de la obra, que una concepción moderna del arte no supo ver, ha quedado patente que una interpretación orientada exclusivamente hacia el contenido no es suficiente para expli-

${ }^{4}$ Ulrich GaIer, Studien zu Sebastian Brants Narrenschiff, Tübingen, 1966; y Satire. Studien zu Neidhart, Wittenweiler, Brant und zur satirischen Schreibart, Tübingen, 1967. 
car el alcance y el éxito singular de este poema de "locos". Además, los frutos de esta investigación nos hacen comprender de mejor manera por qué los humanistas seguidores de la poesía clásica alabaron esta obra como una valiosa creación artística de la literatura.

No sería pertinente referir aquí los resultados de otras investigaciones sobre La nave de los locos, así como sobre la temática del "loco". No obstante, señalamos el breve pero valioso tomo sobre La nave de los locos de Klaus Manger ${ }^{5}$, que resume los diferentes enfoques de la investigación. Al considerar la obra como una " biblia secular" y una sátira con la que su autor promueve el mensaje cristiano, Manger estima que la unidad de la obra de Brant radica en esta tendencia parenética, así como en la emulación de la navegación espiritual bajo la apariencia de la navegación de los "locos". Su libro resulta, además, extraordinariamente útil como obra de consulta, ya que contiene una lista completa de las ediciones y traducciones de La nave de los locos y un cuadro sinóptico del orden de los capítulos según las diferentes ediciones, amén de una amplia y completa bibliografía que llega hasta el año de 1983.

Universidad de Heidelberg

JORN REICHEL

Traducción de Klaus Wagner (Universidad de Sevilla).

${ }^{5}$ Klaus Manger, Das 'Narrenschiff'. Entstehung, Wirkung und Deutung, Darmstadt, 1983. 